American Journal of Pharmaceutical Education 2018; 82 (9) Article 7014.

\title{
COMMENTARY
}

\section{A Call to Action to Transform Pharmacy Education and Practice in the Arab World}

\author{
Abeer M. Al-Ghananeem, PhD, ${ }^{a}$ Daniel R. Malcom, PharmD, ${ }^{\text {be }}$ Samira Shammas, BSPharm, \\ Talal Aburjai, $\mathrm{PhD}^{\mathrm{d}}$ \\ a Jordan University of Science and Technology, Irbid, Jordan \\ ${ }^{\mathrm{b}}$ Sullivan University College of Pharmacy, Louisville, Kentucky \\ ${ }^{\mathrm{c}}$ Jordan Pharmacists Association, Good Pharmacy Practice Committee, Amman, Jordan \\ ${ }^{\mathrm{d}}$ Middle East University, Amman, Jordan \\ e Associate Editor, American Journal of Pharmaceutical Education, Arlington, Virginia \\ Submitted February 12, 2018; accepted April 22, 2018; published November 2018
}

Globally, pharmacy education is evolving to reflect a more patient-centered, interprofessional approach to clinical practice. In the 22 countries of the Arab world, advancements in regulatory support for pharmacy practice and changes to the health care system have been slower than in Europe, Asia, and the Americas. Significant cultural, logistical, and legal barriers exist in many countries, and a consensus approach to accreditation, educational outcomes, and curricula design is lacking. This commentary briefly examines the current state of both pharmacy education and practice in the Arab world, and it highlights recent reports of curricular reform and innovation. Additionally, it provides potential strategies for improving the quality of education and for expanding pharmacy practice to ensure graduates and practitioners have adequate experiential opportunities and institutional support.

Keywords: international education, Arab world, curricula reform, clinical pharmacy

\section{INTRODUCTION}

Around the world, pharmacy education is undergoing significant transformation to advance the practice of pharmacy and improve patient outcomes. ${ }^{1,2}$ Pharmacists are moving beyond dispensing medications toward more advanced services such as comprehensive medication safety systems, collaborative drug therapy management, and improving transitions of care. ${ }^{3,4}$ However, transforming patient care services require educated and qualified clinical pharmacists as well as trained educators to support their deployment and maintenance. ${ }^{5}$ The educational system and governmental regulatory structures in place should match both the health care needs of the people in a particular country or area and the capabilities and training of the members of the health care team. ${ }^{6}$ This need is especially prominent in the Arab world, which consists of 22 countries in Asia and Africa that share a common history, language, and culture. ${ }^{7}$ In the Arab world, the burdens of chronic diseases such as diabetes, cardiovascular disease, and obesity are growing in addition to poverty, population growth, increasing numbers of refugees,

Corresponding Author: Abeer M. Al-Ghananeem, Jordan University of Science and Technology, Faculty of Pharmacy, PO Box 3030, Irbid 22110, Jordan. Tel: 011962790979255.

E-mail: amalghananeem@just.edu.jo and other public health issues. ${ }^{8,9}$ Certainly, the countries that make up the Arab world are all at different stages of growth, have different governmental systems, and often different local problems that need addressing. However, as geographic neighbors sharing a similar climate, history, culture, economy, and even population, the commonalities between these countries are significant, as well as the challenges and opportunities they face.

\section{Health Care and Pharmacy Education in the Arab World Demographic Changes}

Unlike many countries in the developed world, the Arab world has shifted demographically toward younger people, with some countries having up to $50 \%$ of the population below age $30 .{ }^{10}$ Improvements in infant mortality rates coupled with increased access to health care and other resources (particularly in urban areas) have largely contributed to this shift. Immigration is also a significant factor in the population makeup of the Arab world, with some countries having upward of $50 \%$ to $70 \%$ expatriates as residents. ${ }^{11}$ Of the six countries in the Gulf Cooperation Council (GCC), which include Bahrain, Kuwait, Oman, Qatar, Saudi Arabia, and the United Arab Emirates (UAE), the UAE has the highest percentage of expatriates as 


\section{American Journal of Pharmaceutical Education 2018; 82 (9) Article 7014.}

residents at nearly $90 \% .{ }^{12}$ The governments of these countries have increased spending on health care infrastructure dramatically in the past 20-25 years by building hospitals, clinics, and new educational centers to train health care professionals in efforts to improve the quality of life of their citizens and minimize their dependence on expatriates for labor in health care. ${ }^{9}$

\section{Pharmacy Practice in the Arab World}

Comprehensive reviews of the scope and depth of pharmacy practice across the Arab world are lacking. However, several recent articles and book chapters cite experiences in select countries. ${ }^{13-19}$ Employment opportunities for pharmacists in the Arab world are similar to those in other parts of the world, including community and institutional practice, as well as in the regulatory, academia, and industry fields. ${ }^{20}$ Some countries, including Egypt, Lebanon, and Jordan have placed restrictions on licensing and practicing expatriates. In many cases, these countries train pharmacists to work in other countries (as well as within their own borders), which serves as a type of "exporting" of labor. Other smaller countries such as the UAE, Qatar, and Bahrain then "import" these trained pharmacists. A 2016 report cited Saudi Arabia as having 22,241 pharmacists, of which only $20.6 \%$ were Saudis. ${ }^{13}$ Generally, changes and developments in pharmacy practice in the Arab world have been slower when compared with other places. ${ }^{16,19,20}$ Most pharmacists work in the community setting, and most community pharmacies are privately owned. Chain pharmacies have begun to show growth in certain countries (particularly in urban areas and malls), but they have not taken over the majority of pharmacies in most places. Like in other parts of the world, hospital pharmacy practice is generally more advanced than community practice, and pharmacists in those settings are more likely to have an advanced degree or residency training. ${ }^{16,19,20}$

\section{Barriers to Clinical Pharmacy Practice}

Multiple barriers exist in the Arab world that hinder the full implementation of clinical pharmacy education and practice, including lack of sufficient experiential training within pharmacy curricula and regulatory restrictions on new graduates (and expatriates) opening or managing community pharmacies. ${ }^{16,19,20}$ These barriers are multi-factorial in nature; however, their impact on clinical practice and patient outcomes is evident. Paravattil and colleagues used simulated patients in the community pharmacy setting in Qatar to explore characteristics affecting the quality of counseling received. ${ }^{21}$ In their study, 129 of 136 pharmacists (94\%) consented to participate, with the majority being male $(65.9 \%)$, aged 40 or younger (84.5\%), and trained in India or Egypt (73.7\%).
Only $3.9 \%$ of the pharmacists had a doctor of pharmacy (PharmD) degree, while $90.7 \%$ had a bachelor of science in pharmacy (BPharm). Eighty-one percent of pharmacists scored $<35 \%$ on a scoring sheet quantifying the type and amount of information provided in the counseling session. Information most likely missed in the counseling included drug contraindications, information regarding missed doses, and refill information. In Qatar, as in other countries of the Arab world, it is not required by law for pharmacists to counsel patients, and it is uncommon for community pharmacies to keep patient records of any type or use any type of computerized database to check for potential pharmacy drug interactions. A 2017 study in Lebanon found that the general public had a very poor understanding of the pharmacist's role and only few perceived the pharmacist as significantly knowledgeable to answer their questions. ${ }^{22}$ A 2014 study in Egypt showed that only $60 \%$ of physicians surveyed were aware of the discipline of clinical pharmacy, and slightly over $50 \%$ of physicians surveyed believed that the clinical pharmacist could be a good source of drug information. ${ }^{23}$ Pharmacists across the Arab world have significant barriers in terms of public image to overcome, as well as perception of services among health care providers.

\section{Evolution of Pharmacy Programs}

According to data from the International Pharmaceutical Federation (FIP), there are 126 pharmacy programs in the 22 countries of the Arab world. ${ }^{24}$ Most of these pharmacy programs have been established within the last 20 to 30 years. ${ }^{20,25,26}$ For example, in Kuwait, no pharmacy program existed prior to 1996, and most pharmacists working in Kuwait were trained outside the country. ${ }^{20}$ The significant costs involved in training pharmacists in other countries led the government to establish the Faculty of Pharmacy at Kuwait University in $1996 .{ }^{27}$ In 2000, the Faculty of Pharmacy at Jordan University of Science and Technology was the first to offer a PharmD program, which was six years in length. ${ }^{28}$ In Saudi Arabia, which only had one pharmacy school until 2001 (King Saud University in Riyadh), a 2018 study reported that 23 government-run and seven private colleges had opened since $2001 .^{29}$ Most of these newer programs offer a fiveor six-year PharmD and other undergraduate and graduate degrees in pharmacy-related disciplines. Unlike other Middle Eastern countries, Lebanon has had a long history of pharmacy education. ${ }^{30}$ Université Saint Joseph founded the first pharmacy program in Lebanon in 1912, with another private program that opened in 1987 at Beirut Arab University. ${ }^{30}$ Lebanese American University (LAU) opened in Byblos, Lebanon in 1993 and its PharmD program has been accredited by the Accreditation Council of 


\section{American Journal of Pharmaceutical Education 2018; 82 (9) Article 7014.}

Pharmacy Education (ACPE) since 2002 (and remains the only international program to hold that accreditation). ${ }^{31}$ LAU offers a five-year BPharm degree and a six-year PharmD, with only the PharmD program holding ACPE accreditation. $^{31}$

\section{Lack of Preceptors and Practice Sites}

Multiple reports cite lack of sufficient educators with the appropriate training in clinical disciplines such as patient assessment, communication skills, and therapeutics as well as clinical preceptors with advanced training in the Arab world. ${ }^{13,19,20,25,29,30}$ A 2009 review of pharmacy programs in 12 Middle Eastern countries also showed significant variability in experiential requirements, with no structured mentorship or clear expectations of contact time during experiences. ${ }^{20}$ Often, these experiences lack sufficient organization and specific learning objectives and outcomes. ${ }^{20}$ Practice sites, whether community, institutional, or other setting, do not have consistent standards for services provided or standardized educational outcomes to which learning activities can be mapped and tracked for quality assurance and performance improvement.

\section{Curricular Reform}

Several recent reports highlight curricular innovation and transformation efforts at pharmacy programs in the Arab world. Sobh and colleagues described the implementation and validation of cumulative objective structured clinical examinations (OSCEs) at a pharmacy program in Qatar. ${ }^{32}$ Shahiwala described a project-driven activity implemented at a pharmacy school in Dubai, UAE with a purpose of building entrepreneurship skills in students. ${ }^{33}$ However, a review by Bajis and colleagues described the lack of literature on competency-based education in the Eastern Mediterranean region, which includes many countries of the Arab world. ${ }^{34}$ While curricular transformation is beginning and ongoing, many programs continue to offer a traditional pharmacy education with emphasis on drug preparation and compounding. ${ }^{20,25}$ Several organizations are working to enhance pharmacy education globally including the FIP, the World Health Organization (WHO), ACPE, the Association of Pharmacy Colleges in the Arab world, and the American Association of Colleges of Pharmacy (AACP) ${ }^{35-37}$ The global vision developed by these groups is designed to promote workforce development in the context of pharmaceutical education and training. ${ }^{38,39}$ Additionally, this vision will assist professional leadership bodies, educators, and regulators in developing a national or regional vision based on the priorities and resources of the country or region, with the aim of improving their performance for better health.

\section{Recent Developments}

While pharmacy education in the Middle East continues to evolve, advancement toward more clinically oriented and patient-centered educational outcomes is critical to keep pace with health care demands in the region. This need is particularly noticeable in areas of high population density and poverty such as refugee camps, the need for which has grown recently due to the Syrian civil war and other conflicts. ${ }^{40,41}$ Nearly six million Syrians have left the country to-date, while an additional 10 million have been displaced from their homes within the country. While some refugees have relocated to Europe or even North and South America or Asia, many have fled to neighboring Middle Eastern countries. ${ }^{42,43}$ In these areas, the additional influx of people has increased the strain on resources including schools, food and health care. ${ }^{44,45}$ Despite these challenges, pharmacy is uniquely positioned to make a difference. In many countries of the Arab world, medications are classified as "prescription" drugs but are often available for sale in pharmacies without a prescription. ${ }^{46-49}$ Where legal and authorized, this practice provides an opportunity for pharmacists to enhance the level of care provided to patients, particularly in areas where infrastructure and comprehensive medical services are either unavailable or disrupted by ongoing conflicts.

\section{Recommendations}

To meet the patient care and educational needs of countries in the Arab world and overcome key barriers, the authors have identified six key strategies. These can apply to other regions of the world as well.

Develop and implement competency-based pharmacy education to better prepare pharmacists for their role as a part of the health care system. One of the areas needing improvement is developing and implementing quality assurance metrics to assess clinical skills competencies throughout the didactic and experiential curriculum. This will require recruiting and training qualified faculty, as well as seeking more guidance from the international pharmacy education and accreditation communities. ACPE established the International Services Program in 2011 to provide consultation and training related to quality assurance and improving pharmacy education worldwide. ${ }^{50}$ In August 2017, a memorandum of affiliation (MoA) was signed between ACPE and the Council for Higher Education Accreditation (CHEA) International Quality Group (CIQC). This MoA and other international outreach efforts will offer exchange of experience, enhance standardized training of local educators, and develop metrics that are aligned with the local culture and practice, and regional standards. ${ }^{51}$ Sharing 


\section{American Journal of Pharmaceutical Education 2018; 82 (9) Article 7014.}

those metrics will help build a firm foundation upon which future growth can happen.

Define new, improved learning outcomes for clinical pharmacy education and reassess the teaching methods and learning environment. This would require using innovative teaching techniques to enrich students' problem-solving skills, critical thinking, reflection and self-awareness, personal learning skills, and communication skills. While reports of efforts to incorporate these concepts into pharmacy curricula within institutions in the Arab world have recently been published, systematic adoption of shared learning outcomes across the region is still lacking. ${ }^{52-54}$ Transforming delivery of content in pharmacy curricula is also crucial to standardizing education in the Arab world. In their 2017 study, Nasr and Wilby described incorporating problem-based learning into a pharmacy curriculum in Qatar. ${ }^{54}$ They identified an additional educational challenge related to using or attempting to use Western cultural norms in other contexts. ${ }^{54}$ In the Arab world, differences related to collectivism vs. individualism, gender roles, and power-distance may introduce different issues with using active learning techniques than in other areas of the world. Nasr and Wilby recommend that educational designers examine local cultural practices as a part of the process and adapt techniques to maximize engagement while respecting beliefs and cultural norms. ${ }^{54}$

Strengthen experiential and interprofessional education (IPE) through strategic planning and leveraging resources. Pharmacy programs should seek advanced training opportunities for current and future educators and preceptors, work with relevant governmental bodies to credential educators as appropriate, and provide IPE opportunities. By identifying current advanced training opportunities in each country and in the region, it is possible to better collaborate among schools to provide quality experiential experiences. Recent reports cite a significant gap in new pharmacy graduates' preparation to practice. ${ }^{55,56}$ Quality experiential and IPE opportunities are vital to prepare pharmacists who will be ready to work as effective members of the healthcare team. The 2010 WHO Framework for Action on Interprofessional Education and Collaborative Practice highlights the vital role of incorporating IPE into health care to prepare a workforce best able to face complex health challenges. ${ }^{57}$ For an IPE model to be effective, it should be carefully tailored to the special needs of patients without compromising care standards. Recent efforts highlight successes in incorporating IPE into both clinical and educational practice, but significant improvement is still needed. ${ }^{58-62}$ Some challenges are a lack of standardized educational outcomes related to IPE, limited or nonexistent simulation laboratories, and informal standardized participant programs. ${ }^{60}$

Develop and implement quality continuous professional development (CPD) programs as part of licensure renewal. In the Arab world, as in the rest of the world, CPD is of vital importance to augment knowledge and patientcentered practice for all pharmacists. CPD is especially important for BPharm graduates who represent majority of practicing pharmacists. In many jurisdictions, CPD is recommended, but not required for license renewal. ${ }^{63-65}$ Even within some countries, requirements can differ. In the UAE, for example, Abu Dhabi, the largest emirate, instituted a requirement for 20 hours of annual CPD credit in $2009 .{ }^{64}$ Other emirates have not had such a requirement. ${ }^{15}$ Improving the quality of CPD would require identifying disease burdens and public health issues in each country and the region, compiling a list of experts in the region who can provide $C P D$, identifying best practices in CPD, and providing purposeful programming to address both identified as well as future needs. Collaboration with academia is critical to make such efforts successful.

Develop accreditation standards and quality assurance guidelines locally and regionally to address and standardize pharmacy education and practice. This must be accomplished by engaging all stakeholders including pharmacy educators, practitioners, government, educational and practice organizations, and health systems in establishing accreditation standards that meet the needs of the region. The Association of Pharmacy Colleges in the Arab World has the potential to take the lead in establishing such accreditation standards or guidelines. Involving key stakeholders such as ACPE and the FIP Global Pharmacy Education Taskforce could also help pharmacy programs in the Middle East learn from the experience of other countries and recommendations from global organizations. This recommendation does not purport that specific curricula should be prescribed; however, much like ACPE Standards in the US, creating a specific set of standards would provide a common "language" that faculty, administrators, students, and stakeholders could use to establish clear expectations for both didactic and experiential learning. Given the prominent place of immigration and the large proportion of expatriates working as pharmacists and attending pharmacy school outside of their home country, common accreditation standards could also be very helpful in creating a uniform picture of the role and expectations of a pharmacist, allowing a more concerted and focused approach to advancing practice. ${ }^{10-12}$

Create job opportunities for new graduates aligned with their new knowledge and skills sets. Accomplishing this goal will require constructive dialogue between academia, practice, and government to create such opportunities 


\section{American Journal of Pharmaceutical Education 2018; 82 (9) Article 7014.}

and to encourage new graduates to seek them. It is understandably frustrating for new graduates to enter into practice in settings that do not fully utilize their advanced training and skills. Opportunities to expand practice in these countries should be linked to local health care needs and available infrastructure. ${ }^{9}$ All members of the pharmacy profession must work in concert to change the image of pharmacy as a profession. ${ }^{22,23}$ In addition to educating stakeholders with the role pharmacy can play in optimizing patient care, addressing public health issues and collaborating with physicians and other health care professionals can decrease disease-burden and meet the health care needs of society at large.

\section{CONCLUSION}

Expansion of clinical pharmacy practice has the potential to meet disease-burden and public health issues afflicting countries in the Arab world and globally. While pharmacy in the Arab world has made some strides to meet the needs of the population, there is still need for more consolidated efforts among academia, practice, and government to both improve and standardize the profession and the ability of pharmacists to meet the challenges of the region. The authors hope these recommendations serve as a starting point among key stakeholders to communicate about ways to accomplish these goals.

\section{REFERENCES}

1. Alsharif N. Purposeful global engagement in pharmacy education. Am J Pharm Educ. 2017;81(10):Article 6882.

2. Anderson C, Brock T, Bates I, et al. Transforming health professional education. Am J Pharm Educ. 2011;75(2):Article 22. 3. Toklu HZ, Hussain A. The changing face of pharmacy practice and the need for a new model of pharmacy education. $J$ Young Pharm. 2013;5(2):38-40.

4. McBane SE, Dopp AL, Abe A, et al. Collaborative drug therapy management and comprehensive medication management-2015.

Pharmacotherapy. 2015;35(4):39-50.

5. Keown OP, Parston G, Patel H, et al. Lessons from eight countries on diffusing innovation in health care. Health Aff (Millwood).

2014;33(9):1516-1522.

6. Batniji R, Khatib L, Cammett M, et al. Governance and health in the Arab world. Lancet. 2014;383(9914):343-355.

7. Council on Foreign Relations. The Arab League. https://www.cfr. org/backgrounder/arab-league. Updated 2014. Accessed April 11, 2018. 8. Mokdad AH, Jaber S, Abdel Aziz MI, et al. The state of health in the Arab world, 1990-2010: an analysis of the burden of diseases, injuries, and risk factors. Lancet. 2014;383(9914):309-320.

9. Khoja T, Rawaf S, Qidwai W, Rawaf D, Nanji K, Hamad A. Health care in Gulf Cooperation Council countries: a review of challenges and opportunities. Cureus. 2017;9(8):e1586.

10. Lord K. Here come the young. Foreign Policy. http:// foreignpolicy.com/2016/08/12/here-comes-the-young-youth-bulgedemographics. Published August 12, 2016. Accessed April 11, 2018. 11. Davidson CM. Expatriates and the Gulf monarchies: politics, security and the Arab spring. Asian Aff. 2014;45(2):270-288.
12. Gulf Research Center. GCC: Total population and percentage of nationals and non-nationals in GCC countries. http://gulfmigration. eu/total-population-and-percentage-of-nationals-and-non-nationalsin-gcc-countries-latest-national-statistics-2010-2015. Updated 2015. Accessed April 11, 2018.

13. Al-Jedai A, Qaisi S, Al-Meman A. Pharmacy practice and the health care system in Saudi Arabia. Can J Hosp Pharm. 2016;69(3): 231-237.

14. Fathelrahman AI, Ibrahim MIM, Wertheimer AI. Pharmacy Practice in Developing Countries: Achievements and Challenges. Amsterdam: Elsevier; 2016.

15. Dameh M. Pharmacy in the United Arab Emirates. South Med Rev. 2009;2(1):15-18.

16. Rayes IK, Hassali MA, Abduelkarem AR. The role of pharmacists in developing countries: the current scenario in the United Arab Emirates. Saudi Pharm J. 2015;23(5):470-474.

17. Sadek MM, Elnour AA, Al Kalbani NM. Community pharmacy and the extended community pharmacist practice roles: the UAE experiences. Saudi Pharm J. 2016;24(5):563-570.

18. Kheir N, Fahey M. Pharmacy practice in Qatar: challenges and opportunities. South Med Rev. 2011;4(2):92-96.

19. Abdel-Latif MM, Sabra K. Clinical pharmacy practice in Egyptian hospitals. Am J Health Syst Pharm. 2016;73(1):e63-66. 20. Kheir N, Zaidan M, Younes H, El Hajj M, Wilbur K, Jewesson PJ. Pharmacy education and practice in 13 Middle Eastern countries. Am J Pharm Educ. 2009;72(6):Article 133.

21. Paravattil B, Kheir N, Yousif A. Utilization of simulated patients to assess diabetes and asthma counseling practices among community pharmacists in Qatar. Int J Clin Pharm. 2017;39(4):759-768.

22. Iskandar K, Hallit S, Raad EB, Droubi F, Layoun N, Salameh P. Community pharmacy in Lebanon: a societal perspective. Pharm Pract (Granada). 2017;15(2):893.

23. Sabry NA, Farid SF. The role of clinical pharmacists as perceived by Egyptian physicians. Int J Pharm Pract. 2014;22(5):354-359.

24. International Pharmaceutical Federation (FIP). Official world list of pharmacy schools. http://academic_institutional_membership. fip.org/world-list-of-pharmacy-schools. Accessed April 11, 2018. 25. Al-Wazaify M, Matowe L, Albsoul-Younes A, Al-Omran OA. Pharmacy education in Jordan, Saudi Arabia, and Kuwait. Am J Pharm Educ. 2006;70(1):Article 18.

26. Sarheed O, Al-Azzawi, Nagavi BG. Pharmacy education in the United Arab Emirates. Am J Pharm Educ. 2014;78(2):Article 45.

27. Faculty of Pharmacy at Kuwait University. http://www.hsc.edu. kw/fop. Accessed April 11, 2018.

28. Faculty of Pharmacy at Jordan University of Science and Technology. http://www.just.edu.jo/FacultiesandDepartments/ FacultyofPharmacy/Pages/Highlights.aspx. Accessed April 11, 2018. 29. Alhamoudi A, Alnattah A. Pharmacy education in Saudi Arabia: the past, the present, and the future. Curr Pharm Teach Learn. 2018;10(1):58-60.

30. Khachan V, Saab Y, Sadik F. Pharmacy education in Lebanon. Curr Pharm Teach Learn. 2010;2(3):186-191.

31. Lebanese American University School of Pharmacy. http:// pharmacy.lau.edu.lb/about. Accessed April 11, 2018.

32. Sobh AH, Austin Z, Izham M, Diab M, Wilby KJ. Application of a systematic approach to evaluating psychometric properties of a cumulative exit-from-degree objective structured clinical examination (OSCE). Curr Pharm Teach Learn. 2017;9(6):1091-1098.

33. Shahiwala A. Entrepreneurship skills development through project-based activity in bachelor of pharmacy program. Curr Pharm Teach Learn. 2017;9(4):698-706. 


\section{American Journal of Pharmaceutical Education 2018; 82 (9) Article 7014.}

34. Bajis D, Chaar B, Penm J, Moles R. Competency-based pharmacy education in the Eastern Mediterranean region- a scoping review. Curr Pharm Teach Learn. 2016;8(3):401-428.

35. Anderson C, Bates I, Beck D. FIP roundtable consultation on pharmacy education: developing a global vision and action plan. Intl Pharm J. 2006;20:12-13.

36. Anderson C, Bates I, Beck D, et al. The Who UNESCO FIP pharmacy education taskforce: enabling concerted and collective global action. Am J Pharm Educ. 2008;72(6):Article 127.

37. Bruno A, Bares I, Brock T, Anderson C. Towards a global competency framework. Am J Pharm Educ. 2010;74(3):Article 56. 38. International Pharmaceutical Federation (FIP). FIP Global Statement 2016. http://fip.org/files/fip/PharmacyEducation/ Global_Conference_docs/FIP_global_vision_online_version.pdf. Accessed April 11, 2018.

39. International Pharmaceutical Federation (FIP). Transforming Pharmacy and Pharmaceutical Sciences Education in the Context of Workforce Development. The Hague: International Pharmaceutical Federation; 2017.

40. Brand LA, Lynch M. How the refugee crisis is transforming the Middle East. The Washington Post. https://www.washingtonpost. com/news/monkey-cage/wp/2017/03/30/how-the-refugee-crisis-istransforming-the-middle-east. Published March 30, 2017. Accessed April 11, 2018.

41. Arar R, Hintz L, Norman KP. The real refugee crisis is in the Middle East, not Europe. The Washington Post. https://www. washingtonpost.com/news/monkey-cage/wp/2016/05/14/the-realrefugee-crisis-is-in-the-middle-east-not-europe. Published May 14, 2016. Accessed April 11, 2018.

42. McPhillips D. The tragic numbers behind Syria's refugees. US News and World Report. Published December 19, 2016. https://www. usnews.com/news/best-countries/articles/2016-12-19/countries-hostingthe-highest-proportion-of-syrian-refugees. Accessed April 11, 2018. 43. Situation Syria Regional Refugee Response. United Nations High Commission on Refugees. Updated March 29, 2018. https:// data2.unhcr.org/en/situations/syria. Accessed April 11, 2018. 44. Daher A, Alabbadi I. Investigating the effect of Syrian refugees on the pharmaceutical sector in Jordan. Arch Iran Med. 2017;20(8): 538-546.

45. Doocy S, Lyles E, Akhu-Zaheya L, Burton A, Burnham G. Health service access and utilization among Syrian refugees in Jordan. Int J Equity Health. 2016;15(1):108.

46. Amin ME. Pharmacists' knowledge and interest in developing counseling skills related to oral contraceptives. Int J Clin Pharm. 2016;38(2):395-403.

47. Khalifeh M, Moore ND1, Salameh PR. Self-medication misuse in the Middle East: a systematic literature review. Pharmacol Res Perspect. 2017;5(4):e00323.

48. Aljadhey H, Assiri GA, Mahmoud MA, Al-Aqeel S, Murray M. Self-medication in central Saudi Arabia. Community pharmacy consumers' perspectives. Saudi Med J. 2015;36(3):328-334. 49. Alhomoud F, Aljamea Z, Almahasnah R, Alkhalifah K, Basalelah L, Alhomoud FK. Self-medication and self-prescription with antibiotics in the Middle East-do they really happen? a systematic review of the prevalence, possible reasons, and outcomes. Int J Infect Dis. 2017;57:3-12.

50. Accreditation Council for Pharmacy Education. International Services Program. https://www.acpe-accredit.org/internationalservices-program. Accessed April 11, 2018.

51. ACPE Signs Memorandum of Affiliation (MOA) with CHEA International Quality Group (CIQG) [news release]. Alexandria, VA: Accreditation Council for Pharmacy Education; August 3, 2017. https://www.acpe-accredit.org/pdf/ISP/MOAwithCIQG.pdf.

Accessed April 11, 2018.

52. Alefan Q, Allmam S, Mukattash T, Mhaidat N, Alabbadi I, Rascati K. Pharmacoeconomics education in WHO Eastern Mediterranean region. Curr Pharm Teach Learn. 2015;7(6):819-825. 53. Hoffart N, Doumit R, Nasser SC. Use of storyboards as an active learning strategy in pharmacy and nursing education. Curr Pharm Teach Learn. 2016;8(6):876-884.

54. Nasr Z, Wilby KJ. Introducing problem-based learning into a Canadian-accredited Middle Eastern educational setting. Curr Pharm Teach Learn. 2017;9(4):719-722.

55. Bader LR, McGrath S, Rouse MJ, Anderson C. A conceptual framework toward identifying and analyzing challenges to the advancement of pharmacy. Res Social Adm Pharm. 2017;13(2): 321-331

56. AbuBlan R, Nazer LH, Jaddoua SM, Treish IM. A Hospitalbased pharmacy internship program in Jordan: ten years' experience. Am J Pharm Educ. 2018 publication ahead-of-print.

57. WHO Framework for Action on Interprofessional Education \& Collaborative Practice. Geneva: World Health Organization; 2010.

58. Wilbur K, Hasnani-Samnani Z, Kelly I. Interprofessionaleducation activity among undergraduate nursing and pharmacy students in the Middle East. Nurse Educ. 2015;40(4):163-164.

59. El-Awaisi A, Saffouh El Hajj M, Joseph S, Diack L.

Interprofessional education in the Arabic-speaking Middle East: perspectives of pharmacy academics. J Interprof Care. 2016;30(6): 769-776.

60. El-Awaisi A, Wilby KJ, Wilbur K, El Hajj MS, Awaisu A, Paravattil B. A Middle Eastern journey of integrating interprofessional education into the healthcare curriculum: a SWOC analysis. BMC Med Educ. 2017;17(1):15.

61. Hajjar R, Bassatne A, Cheaito MA, et al. Characterizing the interaction between physicians, pharmacists and pharmaceutical representatives in a middle-income country: a qualitative study. PLoS One. 2017;12(9):e0184662.

62. El-Awaisi A, Awaisu A, El Hajj MS, et al. Delivering tobacco cessation content in the Middle East through interprofessionallearning. Am J Pharm Educ. 2017;81(5):Article 91.

63. Nazer LH, Tuffaha H. Health care and pharmacy practice in Jordan. Can J Hosp Pharm. 2017;70(2):150-155.

64. Hasan S. Continuing education needs assessment of pharmacists in the United Arab Emirates. Pharm World Sci. 2009; 31(6):670-676.

65. Wilbur K, El-Awaisi A, Paravattil B, Zolezzi M, Pawluk S. Contemporary professional skills development for pharmacists in the Middle East. Am J Pharm Educ. 2017;81(10):Article 6042. 